\title{
Using the model for improvement and microsystems analysis methodological framework to examine variation in the pressure transducer management process
}

\author{
Shea Polancich *, Terri Poe, Bruce Von Hagel, Jordan DeMoss \\ Department of Community Health, School of Nursing, University of Alabama at Birmingham Health System, Birmingham, \\ Alabama, United States
}

Received: September 15, 2015

Accepted: October 22, 2015

Online Published: November 1, 2015

DOI: $10.5430 /$ jnep.v6n2p43

URL: http://dx.doi.org/10.5430/jnep.v6n2p43

\begin{abstract}
Background: The pressure transducer is a device used commonly in the critical care areas of a hospital in order to monitor the hemodynamic stability of a patient, in particular the critically ill patient. Because pressure transducers are commonly used, and because of the importance of the monitoring associated with the device, the ability to effectively set up and manage a pressure transducer is important. As such, the process should be examined for consistency, accuracy, and safety. Unfortunately, based upon an appraisal of the current research, there is no evidence in the literature detailing a standardized process for managing the pressure transducer set-up, nor is there a specific recommendation regarding the type of provider who should establish and manage these systems.

Methods: The microsystem analysis and model for improvement (MFI) three guiding questions were used as the methodological framework for determining the extent and organizational risk associated with process variation in the pressure transducer management workflow. In critically ill adult intensive care patients, aged 18 and above, how does variation in the type of provider (Registered Nurse versus Anesthesia Lab Personnel) and workflow process (workflow variation, provided by process flow) for managing pressure transducers impact patient outcomes (rates of infection), process efficiency (measured by staff time for transducer set up and process cost for supplies/equipment), and direct cost of hemodynamic monitoring in a 12-month timeframe?

Results: Process variation in the set-up and management of the pressure transducer throughout the healthcare organization was identified through process and pattern analysis. The results of the analysis highlighted operational inefficiencies and un-necessary workflow variations.

Conclusions: The set-up and management of the pressure transducer process within a healthcare organization is a workflow that should be standardized and reviewed for operational and clinical outcomes. From a broader perspective, this project highlights the importance of analyzing workflow and the importance of decreasing workflow variation.
\end{abstract}

Key Words: Pressure transducer management, Microsystem analysis, Improvement

\footnotetext{
*Correspondence: Shea Polancich; Email: polancs@uab.edu; Address: Department of Community Health, School of Nursing, University of Alabama at Birmingham Health System, Birmingham, Alabama, United States. 


\section{BACKGROUND}

The pressure transducer is used with a vascular or arterial catheter in order to monitor the hemodynamic stability of a patient, in particular the critically ill patient. ${ }^{[1]}$ As an example, an arterial catheter may be connected to a pressure transducer in order to monitor blood pressure including systolic blood pressure, diastolic blood pressure, mean arterial pressure, and pulse pressure. In addition this device allows for frequent blood sampling, and may be used for specific indications such as labile blood pressure, anticipation of hemodynamic instability, titration of vasoactive drugs, and morbid obesity. The most common use of the pressure transducer is to monitor cardiovascular pressure. ${ }^{[1,2]}$

Cardiovascular pressure monitoring has three components. The first convention is that cardiovascular pressures is measured in millimeter $(\mathrm{mm})$ of mercury, with the exception of central venous pressure monitoring which is measured in either $\mathrm{mm}$ of mercury or centimeter $(\mathrm{cm})$ of water. Most cardiovascular pressures are referenced toward the heart or specifically the atria in order to eliminate hydrostatic pressure. Finally, cardiovascular pressure devices should be zeroed to ambient atmospheric pressure so that the values obtained reflect pressures above atmospheric pressure. ${ }^{[2-6]}$

The use of a pressure transducer requires an arterial of central or venous line, a rigid-walled, fluid-filled tubing, a pressure transducer with an automatic flushing system, a pressure bag with pressurized saline, and an electronic transducer display system. The invasive catheter is designed to pick up pressure waves created by the component of the cardiovascular system being monitored. The catheter is connected to the fluid-filled tubing. The column of fluid in the tubing carries the mechanical transmission created to the diaphragm of the pressure transducer. The transducer is the link between the tubing system and the electronic system and which coverts the mechanical signal to an electronic signal. ${ }^{[2-6]}$

In order to obtain accurate readings from a pressure transducer, the cannula should be placed properly in the lumen of an unobstructed vessel, the cannula should not be kinked or obstructed, and it should be connected by short, rigid, wide-bored tubing to the transducer. The tubing and the transducer should be free of air bubbles, and the interface between the fluid and the transducer should accurately transmit deflections. The transducer should be leveled and zeroed to the appropriate point with adequate frequency response. Finally, there should be no zero drift and the monitor should be calibrated accurately. ${ }^{[2-4,7-9]}$

Using the pressure transducer for monitoring hemodynamic stability in a critically ill patient is a process that requires understanding of these underlying principles of cardiovascular system monitoring. This understanding is important given that the management of pressure monitoring is a process that is frequently used in the healthcare setting. As such, the ability to manage a pressure transducer is a process that should be examined for consistency, accuracy, and safety. Unfortunately, based upon an appraisal of the current research, there is no evidence in the literature detailing a standardized process for managing the pressure transducer set-up, nor is there a specific recommendation regarding the type of provider who should establish and manage these systems. ${ }^{[2]}$

The purpose of this study is to examine the process of pressure transducer management in the Intensive Care Unit (ICU) setting of an academic medical center in order to identify and determine if process flow variations exists.

\subsection{Setting}

The setting for this study is an academic medical center in the southeastern United States. The facility under study is a major, urban medical center with 1,157 licensed beds and is the primary trauma and referral center for the state of Alabama.

\section{Microsystems/participating clinical areas and leaders}

For this improvement project, within the described setting, the microsystems analyzed included nine of the ICUs within the organization, as well as the anesthesia lab. Clinical leaders representing each of these areas participated in the analysis. From the nursing units, the nurse manager or assistant nurse manager was the primary representative. A trained improvement facilitator was provided to lead the clinical team in analysis and process flow mapping.

\subsection{Clinical question}

The clinical question for this study is as follows: In critically ill adult intensive care patients, aged 18 and above, how does variation in the type of provider (Registered Nurse versus Anesthesia Lab Personnel) and workflow process (workflow variation, provided by process flow) for managing pressure transducers impact patient outcomes (rates of infection), process efficiency (measured by staff time for transducer set up and process cost for supplies/equipment), and direct cost of hemodynamic monitoring in a 12 month timeframe?

\section{METHODS}

The project was conducted as a descriptive study, and was designed as an improvement project using the methodological framework of the Model for Improvement. ${ }^{[9]}$

\subsection{Participants and recruitment}

Nine patient care units or microsystems out of 52 units (17\%) in the organization were selected for this project. This was 
a convenience sample of units, selected due to the nature of the project. The units were selected to participate based upon operationally meeting the criteria for the improvement study. All nine intensive care unit units provide care to the majority of patients with pressure transducers within the organization. Managers from the nine units were requested to participate by the Chief Nursing Officer (CNO). While the request for participation in the project did initiate from the $\mathrm{CNO}$, the managers were not required to participate. Availability for project meetings was based upon unit needs at the time of the meetings. Managers were also able to send a designee to the meetings if they were unable to attend in person.

\subsection{Study timeline}

This improvement project began in April 2015 and was completed in June 2015, as a three month rapid-cycle improvement study. Outcome data used for the analytical components of the project spanned a 12-month time frame from July 2014 through June of 2015.

\subsection{Institutional Review Board (IRB)}

This study was considered to fall under the auspices of an operational improvement project. As such, projects that are related to process improvement activities with no identifiable patient specific data are excluded from IRB review within the organization.

\subsection{Instruments/Tools}

The only tool used in this project was process flow mapping. ${ }^{[10]}$ Process flow mapping is an improvement tool used to evaluate or analyze a defined operational, clinical process. While there are components of process flow mapping that may be standardized, such as symbols, the mapping process is individualized and process specific. This tool is not amenable to validity and reliability testing.

\subsection{Methodological framework}

This study was conducted using the Model for Improvement (MFI) three guiding questions and the Microsystem Analysis as the methodological approach for examining the clinical question. ${ }^{[9,11]}$ The steps of the process used by the organization integrating this approach will be discussed and detailed. The process flow variation opportunities identified in the pressure transducer management process were uncovered following a response to the MFI three guiding questions and microsystem process flow analysis, the steps of which will be described.

\subsubsection{Microsystems analysis}

The microsystems analysis is a systematic process for examining and quantifying gaps in a process or system. Using the 5 " $\mathrm{P}$ " approach, an in-depth examination of the purpose, providers, processes, patients/populations, and patterns of a small working unit or microsystem is completed. The microsystem approach allows specific detail from the workings of a unit to be uncovered and quantified for variation or gaps in practice or process.

Using this approach, data are collected from organizational systems and collated to determine if there is an area within the microsystem that has opportunity for improvement or is failing to meet organizational expectations for excellence. The focus on the microsystem analysis is patient centric, with the expectation that all the workflow and processes of clinical unit produce the highest quality, safe care for every patient.

Figure 1 depicts the elements of the microsystems 5 "P" approach. ${ }^{[12]}$ Patients flow into a clinical unit that has a defined purpose of goal for care. Once the patient enters the clinical unit, a series of processes provided by a team of professionals occur from an entry point to an exit point in the system. The processes and outcomes of the workflow and patient care result in measurable patterns that may be observed and examined for opportunities or gaps that may occur through process variation or failures to meet standards of care.

\subsubsection{Model for improvement/PDSA}

The Model for Improvement is a methodological framework used for examining and implementing interventions for systems-based, process improvement identified through a systematic process for quantifying gaps or process variation, such as the microsystem analysis. The framework is guided by three questions. The first question, "What am I trying to accomplish", specifies the goal or aim of the improvement. The second question, "How will I know a change is an improvement", quantifies a measurable outcome for the improvement. The final question, "What changes can I implement that will result in an improvement", defines the intervention that will be developed and tested in order to improve an identified gap in a process or system. Using these three guiding questions, a systems-based improvement is developed and tested in small test of change, iterative PlanDo-Study-Act cycles, as exhibited in Figures 2 and 3. ${ }^{[13]}$

\section{MFI Three Guiding question responses for the organiza- tional project}

For this project, the initial question answered in the MFI, was "What am I trying to accomplish?" In examining the pressure transducer management process in this health care system, the answer to the first question was to achieve organizational standardization for the set-up and management of the pressure transducer system in all areas where these pressure systems are used. The second MFI question, "How will I know a change is an improvement?" was answered 
using the operational efficiency metrics of "process cost" for supplies and estimated nursing time, and patient outcomes as evidenced by line infections, primarily the rates of central line infections within the ICU areas studied. The final MFI question of "What changes can I implement that will result in an improvement" was answered following the process flowing mapping resulting from the microsystem analysis of the "Process P".

\section{Patients}

Building a Team to Manage A Panel of Primary Care Patients

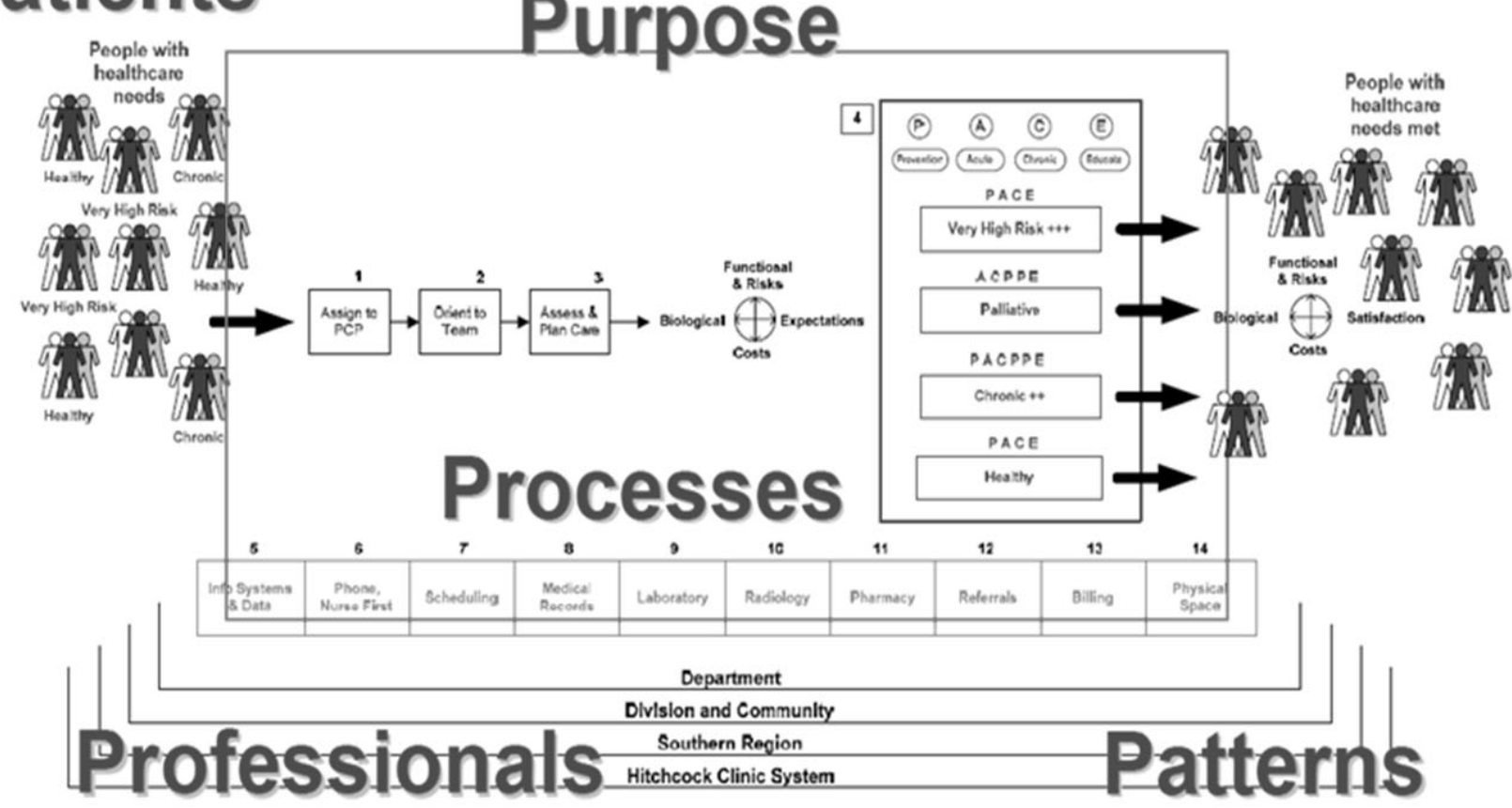

Figure 1. Microsystem 5 P's

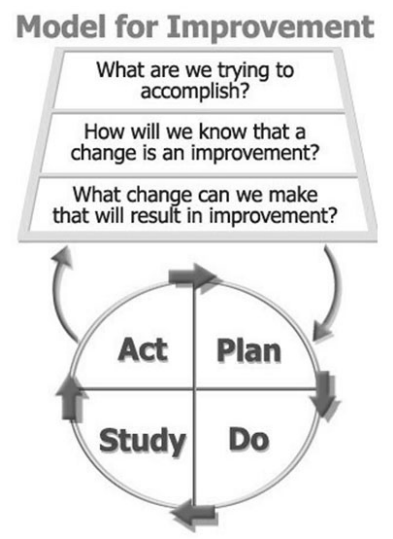

Figure 2. Model for improvement 3 guiding questions and plan-do-study-act (PDSA)

\section{ORgANIZATIONAL IMPROVEMENT PRO- CESS FLOW ANALYSIS}

This improvement study began with a process and cost analysis by an external consultant group on the management of pressure transducers. The external analysis provided enough evidence to support process flow variation, but was not specific enough to determine the extent of the variation at the microsystem level. Given the perceived gap, organizational 46 leadership, which included the $\mathrm{CNO}$ and a hospital administrator, were asked to investigate the current workflow and standard of care/processes surrounding pressure transducer management within the ICU setting across the organization.

At this phase of the project, an improvement facilitator was engaged to quantify the perceived gap using the tools from the microsystem analysis. The improvement facilitator examined the "Process P" of the microsystem through process flow mapping with a small team of providers from each ICU microsystem in the organization. The process flow mapping provided specific details of the workflow within each unit for the set-up and management of the pressure transducer system. The process mapping is provided to show the variations that existed within the workflow in Figures 4-6. Nine ICU microsystems and the anesthesia lab participated in the process flow mapping. These nine areas included: the Trauma/Burn ICU (TBICU), the Bone Marrow Transplant (BMT), unit, the Cardiac Care Unit (CCU), Medical Intensive Care Unit (MICU), Cardiac Intensive Care Unit (CICU), Heart and Lung Transplant Intensive Care Unit (HLTICU), the Neurological Intensive Care Unit (NICU), the Surgical Intensive Care Unit (SICU), Highlands ICU. 


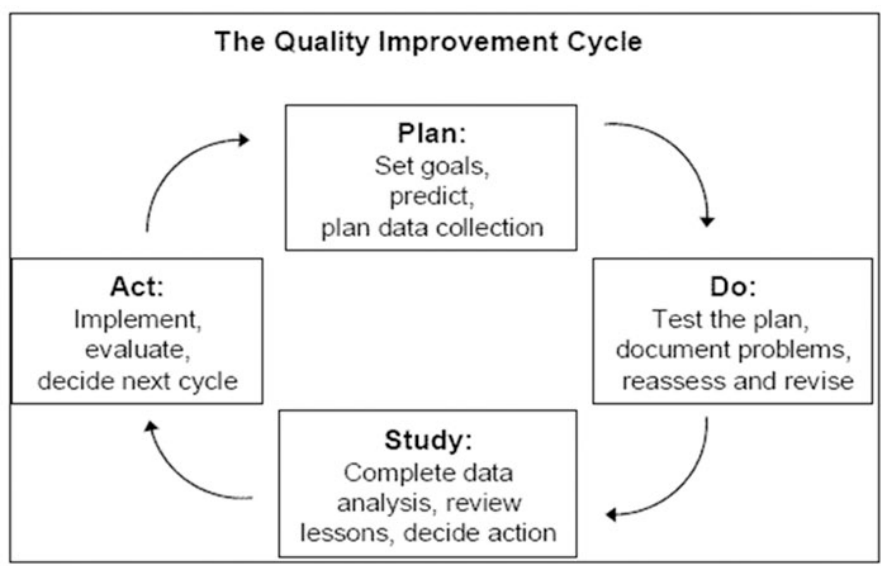

Figure 3. Plan-do-study-act (pdsa) cycle components

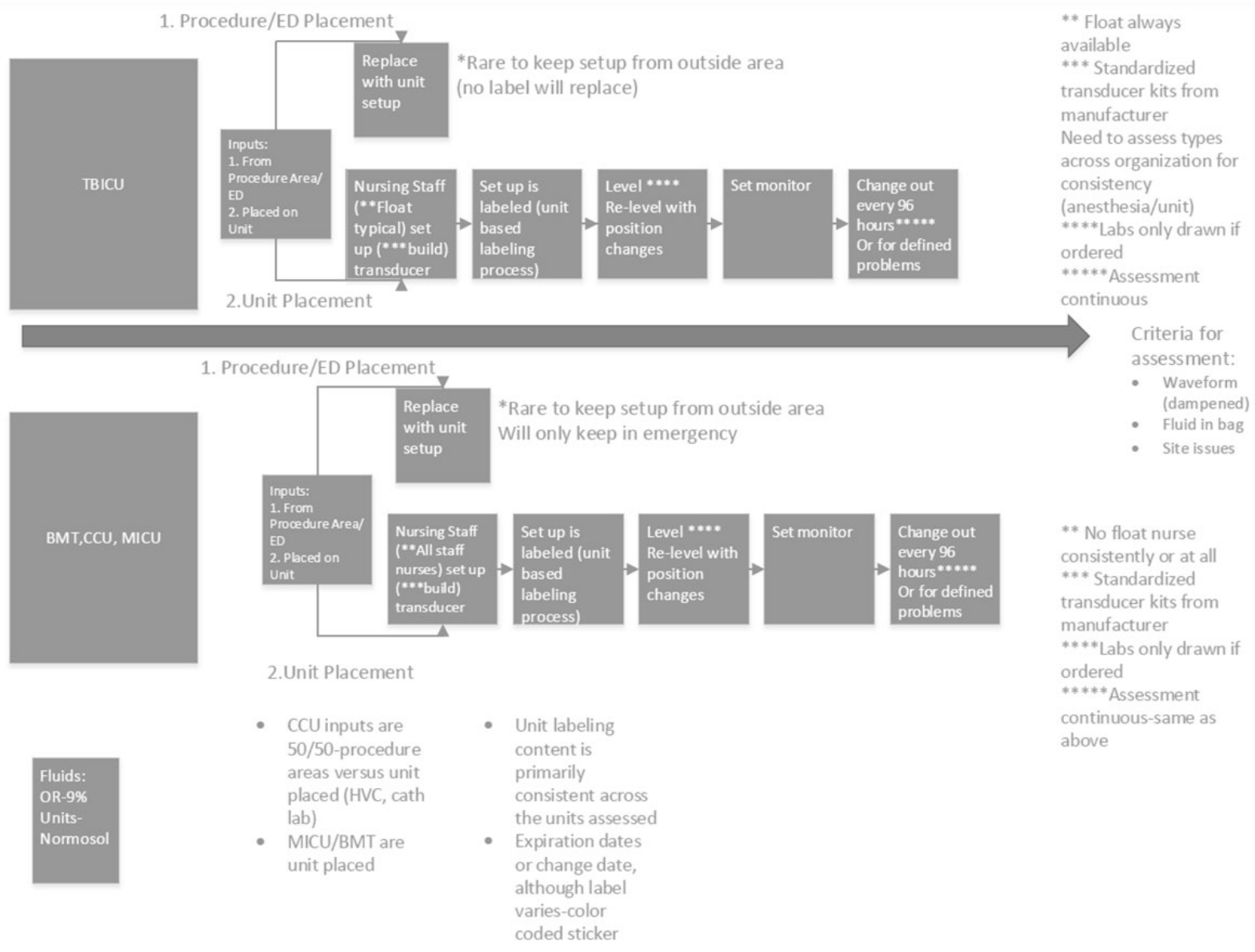

Figure 4. Process flow mapping TBICU, BMT, CCU, MICU

\subsection{Process flow variation identification-gap quantifica- tion}

The process flow mapping provided the evidence to support the perceived lack of standardization or variations in the pressure transducer management process occurring within the ICU microsystems. During the workflow process mapping, the "Provider P" and the "Process P" of the pressure transducer process within the microsystem analyzed were also examined due to identified variations exhibited during the "Process P" analysis, and the results of that analysis will be provided in relation to the process mapping. The following variations were identified: 
- Charge for procedure/task

- Anesthesia lab technicians were able to charge for the task, nursing providers were not, considered part of room charge

- Staff who perform task (varying types and roles)

- 2 different provider types managed the processanesthesia lab technicians and registered nurses were both providers performing the process of pressure transducer management

- Set-up labeling

- What was labeled varied, with some units labeling the date to change the set-up, to the date the set-up was placed

- How the labeling was done varied, with some units using a colored sticker to some units using a "change date" labeled sticker

- Supplies/Equipment

- Supplies varied, with nursing units having more consistent supplies/equipment and the operating room (one area) having different supplies/equipment

* Normosol fluid used by nursing units

* .9\% Sodium Chloride used by operating room (anesthesia lab)

- Education/Competency Assessment

- Inconsistent process for assessing competency on nursing unit, but primarily observational

- Anesthesia lab had written, required competencies, with annual assessment, and new employee (technician) monitoring for 6 months

\section{- Process/Cost Variation}

- Anesthesia management of process in two nursing units (CICU, SICU)

- Some nursing units automatically replaced the set-up with a unit set-up upon admission to the unit from another area, while other areas did not replace unless the set-up had reached the required 96 hour change timeline (as required by organizational policy for replacement of lines and pressure monitoring system)

* 4 units $(44.4 \%)$ replaced transducers automatically upon admission to unit

* 4 units (44.4\%) did not replace transducers automatically upon admission to unit

* 1 unit $(11.1 \%)$ had only unit based placement of transducers (would not receive patients from another area or unit)

- Cost varied due to differences in supplies used
* Operating room (anesthesia lab) transducer supplies varied from nursing unit transducer supplies

* Fluids used in set-up varied from operating room (anesthesia lab) to nursing units

- Cost of supplies varied due to automatic replacement of transducer pressure set-up in 4 of the units-Redundancy Cost Calculation

* Calculation is based upon an average of 5 replacement of the pressure transducer system per day per unit

* Cost of supplies is rounded to $\$ 27.00$ per set up (supplies and fluids), then $\$ 27.00 \times 5$ $=\$ 135.00$ per day $\times 4$ units $=\$ 540.00$ per day

- Supply cost breakdown: Average cost for transducer pressure system $\$ 18.00$ (taking into account the single lumen, double lumen, and triple lumen catheters used in the system)

* Over a 12 month time period, cost savings could potentially reach $\$ 540.00 \times 300$ days (calculating that not every day will require 5 replacements per unit $)=\$ 162,000.00$ per year

- Cost of the process varied due to the automatic replacement of the set-up in certain microsystems, if the automatic replacement of the set-up on the 4 units were estimated the following time-related cost difference may occur:

* If the average cost of nursing time per hour is $\$ 20.00 / \mathrm{hr}$ and the time for transducer setup is 30 minutes, then $\$ 10$ can be estimated for nursing time for each placement.

* If there are 5 replacements per day per unit $\times \$ 10.00=\$ 50.00$ per day

$* \$ 50.00$ per day $\times 4$ units $=\$ 200.00$ per day

$* \$ 200.00 /$ day $\times 300$ days $=\$ 60,000.00$ per year just on the nursing time

\subsection{Data analysis}

An analysis of several variables used in measurement component was completed during the project. The information on the variables reviewed will be discussed as the review of this information was imperative in establishment of equivalence for the replacement and non-replacement units.

\subsubsection{Central venous line days}

In order to assess the equivalence of the central venous line days between the replacement versus the non-replacement 
units, data were obtained from one of the organizations in- and non-replacement units had a total of 12 data points for formation systems. The McKesson (C) system is one of the the twelve month period, totaling 48 data points of central vended information systems within the organization, and venous line days for the grouped units. A line day is defined is used to house and track the volume of central line days. in this project as "a 24 hour period in which a central venous Data were obtained for a 12-month time frame spanning July line is functional within an adult inpatient".

2014 through June of 2015. Each of the four replacement

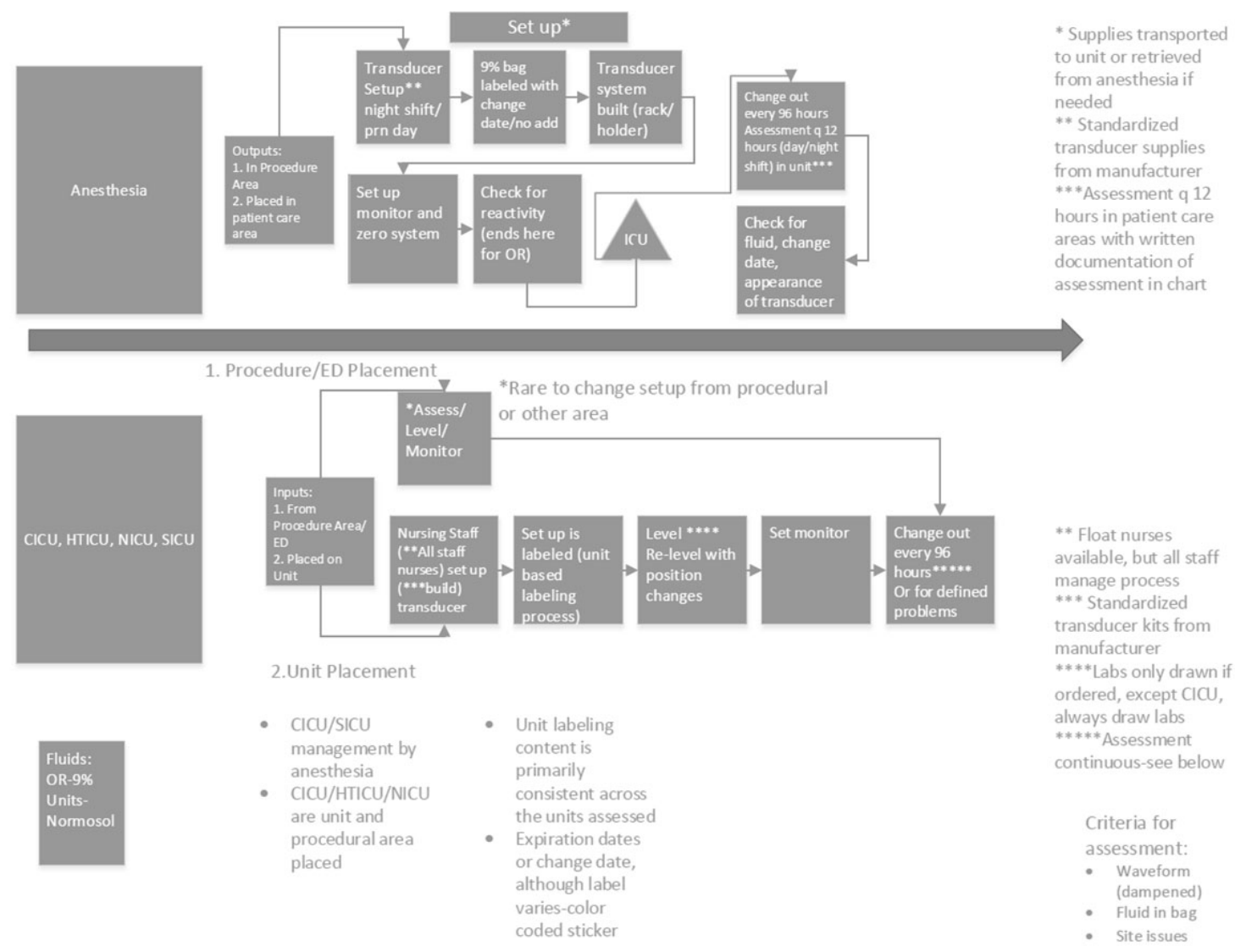

Figure 5. Process flow mapping anesthesia, CICU, HLTICU, NICU, SICU

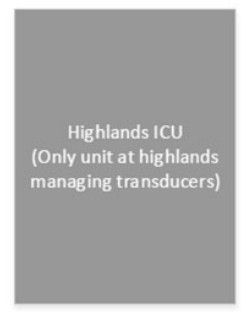

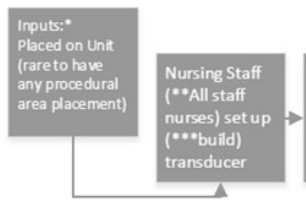
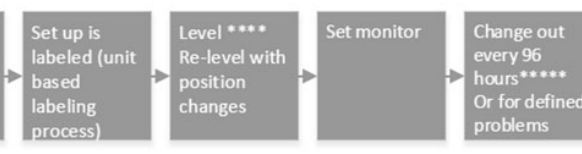

1. Unit Placement

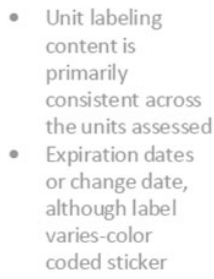

*Highlands would not likely have a setup

placed outside the unit

${ }^{* *}$ No float nurse consistently or at all

*** Standardized

transducer kits from manufacturer

****Labs only drawn if ordered

*****Assessment continuous-see below

Criteria for assessment: - Waveform (dampened) - Fluid in bas - Site issues

Figure 6. Process flow mapping highlands ICU 
Descriptive statistics were used to analyze the mean, median, statistics were analyzed for each of the two groupings showmode, minimum and maximum values for the number of ing an overall mean for the 12 month period to be $\bar{x}=413$ for central line days, in a 12 month period, for each of the nine the "replacement" unit and $\bar{x}=422$ for the "non-replacement" intensive care areas (see Table 1). In addition, descriptive units (see Table 2).

Table 1. Central line days by unit 12-month period July 2014-June 2015

\begin{tabular}{llllll}
\hline Unit & Mean Central Line Days & Median Central Line Days & Standard Deviation(SD) & Minimum & Maximum \\
\hline CCU & 286 & 289 & 36.9 & 206 & 356 \\
CICU & 468 & 462 & 42.2 & 394 & 539 \\
SICU & 401 & 400 & 45.4 & 333 & 480 \\
BMT & 445 & 448 & 35.3 & 373 & 499 \\
MICU & 521 & 525 & 46.9 & 397 & 563 \\
HTICU & 422 & 423 & 32.2 & 356 & 465 \\
NICU & 399 & 395 & 85.2 & 243 & 552 \\
TBICU & 399 & 358 & 89.2 & 287 & 522 \\
Highlands & 86 & 106 & 42.3 & 25 & 147 \\
\hline
\end{tabular}

Table 2. Output group statistics replacement versus non-replacement units

\begin{tabular}{llllll}
\hline Replacement Unit Versus Non-Replacement Unit & N & Mean & Std. Deviation & St. Error Mean \\
\hline \multirow{2}{*}{ Central Line Days } & Replacement & 48 & 412.75 & 102.038 & 14.728 \\
& Non-Replacement & 48 & 422.44 & 60.183 & 8.687 \\
\hline
\end{tabular}

In order to compare the means of the groups, two different analytical processes were completed using the Statistical Program for the Social Sciences (SPSS) version 22. Because the Highlands unit is much smaller in volume, this group was excluded from an initial independent samples $t$-test comparing the "replacement" versus "non-replacement" units. The distribution of the 48 data points for each group appeared

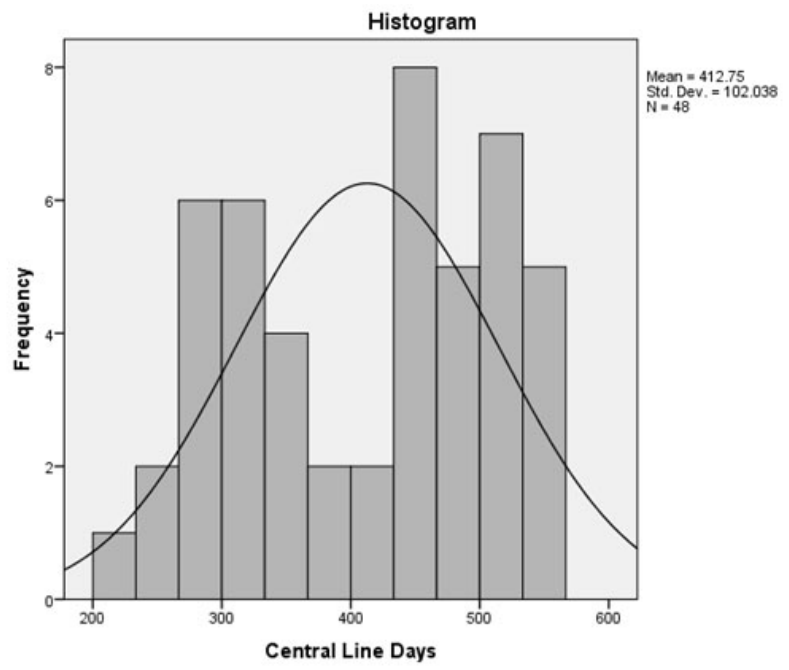

normally distributed (see Figure 7), and the " $\mathrm{N}$ " is greater than 30 points for each grouping. However, the homogeneity of variance was statistically significant $p=.001$, showing that there is a difference in the variances of the two groups. However, using the "equal variances not assumed" component of the independent samples $t$-test, the groups were found to be similar with a $p=.573$.

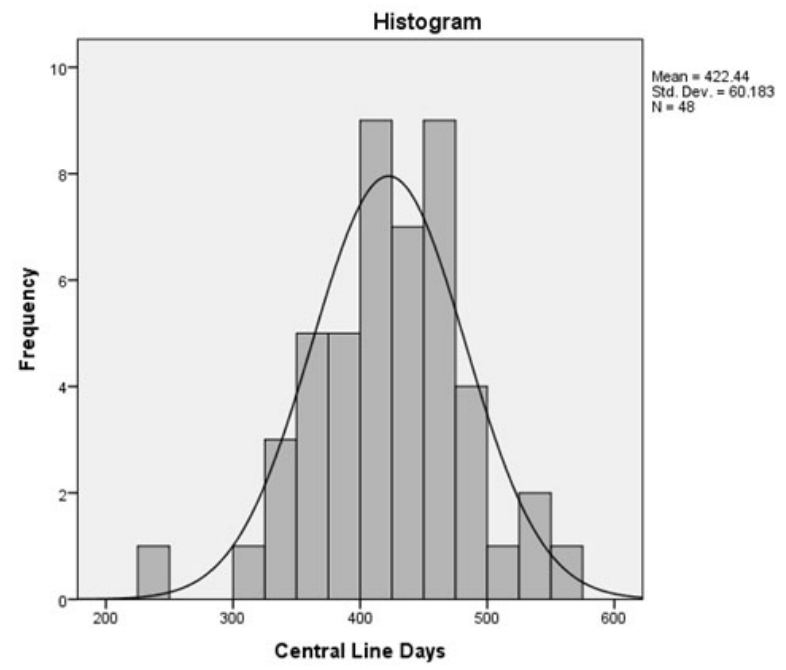

Figure 7. Distribution of central line days "replacement" versus "non-replacement units" 
In addition to the independent samples $t$-test, an Analysis of Variance (ANOVA) was also completed adding the single "Unit Placed" group for the Highlands ICU. It is noted that these data are an outlier because the unit volume is considerably lower. While the ANOVA may be considered less robust due to the smaller " $\mathrm{N}$ " of the outlier unit, the results do produce outcomes consistent with a statistically significant difference in the three units based upon central line day volume. This may be significant when the rates of line infections are compared.

The ANOVA does show a statistically significant difference in line days between the three groups with a $p=.001$ (see Table 3). Post-hoc testing using Sidak's for non-equal "N's" showed a statistically significant difference between the replacement and non-replacement units and the unit placed areas with a $p=.001$. There was no statistically significant difference between the replacement and non-replacement units in this comparison as well with a $p=.913$ (see Table $4)$.

These data support the assumption that the central line days for replacement and the non-replacement units were similar, with the unit placement location being an outlier in volume. However, more importantly these data support the equivalence of the replacement versus non-replacement units when comparing volume of line days, and will be used to support an equivalent environment for comparing central line infection rates.

\subsubsection{Central venous line infections}

Central venous line infections were also compared for this project as an outcome indicator for the equivalence of the units. In light of the process variation, it was hypothesized by the improvement team that the transducer pressure management process could be standardized to a non-replacement process if the units were similar in infection rates. In addition, analyzing data on these units would also disprove the foundation for the "automatic" replacement that was steeped in routine or fear of added patient risk for infection and not grounded in evidence. Table 5 provides data on the rates of central venous line infections for the "replacement" and the "non-replacement" units. These data were masked to protect the unit data for the organization, and the "unit placement only" was not included.

Table 3. ANOVA central line days three group comparison

\begin{tabular}{llllll}
\hline & Sum of Squares & df & Mean Square & F & Sig. \\
\hline Between Groups & $1,174,510.012$ & 2 & $587,255.006$ & 90.779 & .000 \\
Within Groups & $679,251.729$ & 105 & $6,459.064$ & & \\
Total & $1,853,761.741$ & 107 & & & \\
\hline
\end{tabular}

Table 4. Post-hoc comparison of central line days ANOVA

\begin{tabular}{|c|c|c|c|c|c|c|}
\hline \multirow{2}{*}{$\begin{array}{l}\text { (I) Replacement Unit vs. } \\
\text { Non-Replacement Unit }\end{array}$} & \multirow{2}{*}{$\begin{array}{l}\text { (J)Replacement Unit } v s . \\
\text { Non-Replacement Unit }\end{array}$} & \multirow{2}{*}{$\begin{array}{l}\text { Mean Difference } \\
\text { (I-J) }\end{array}$} & \multirow{2}{*}{$\begin{array}{l}\text { Std. } \\
\text { Error }\end{array}$} & \multirow{2}{*}{ Sig } & \multicolumn{2}{|c|}{ 95\% Confidence Interval } \\
\hline & & & & & Lower Bound & Upper Bound \\
\hline \multirow{2}{*}{ Replacement } & Non-Replacement & -9.688 & 16.418 & .913 & -49.52 & 30.15 \\
\hline & Unit Placed Only & $326.667^{*}$ & 25.959 & .000 & 263.68 & 389.65 \\
\hline \multirow{2}{*}{ Non-Replacement } & Replacement & 9.688 & 16.418 & .913 & -30.15 & 49.52 \\
\hline & Unit Placed Only & $336.354 *$ & 25.959 & .000 & 273.37 & 399.34 \\
\hline \multirow{2}{*}{ Unit Placed Only } & Replacement & $-326.667^{*}$ & 25.959 & .000 & -389.65 & -263.68 \\
\hline & Non-Replacement & $-336.354 *$ & 25.959 & .000 & -399.34 & -273.37 \\
\hline
\end{tabular}

*The mean difference is significant at the 0.05 level

Table 5. Central venous line infection data "replacement" versus "non-replacement" units

\begin{tabular}{lll}
\hline Unit & $\begin{array}{l}\text { 12 Month Rate (July 2014-June 2015) } \\
\text { \# of CVL Infections/\# Line Days per unit }\end{array}$ & Days since last line infection \\
\hline Replacement 1 & $0.12 \%$ & 181 \\
Replacement 2 & $0.58 \%$ & \\
Replacement 3 & $0.24 \%$ & $*$ \\
Replacement 4 & $0.04 \%$ & 30 \\
Non-Replacement 1 & $0.27 \%$ & $*$ \\
Non-Replacement 2 & $0.12 \%$ & 122 \\
Non-Replacement 3 & $0.04 \%$ & 30 \\
Non-Replacement 4 & $0.08 \%$ & \\
\hline
\end{tabular}

*Longest days since, prior to June 2015 
Two of the units, one "replacement" and one "nonreplacement" unit prior to June 2015, had been infection free for 304 days. Both units had a single infection in June 2015, starting the count over.

Using the same process to determine if there was a statistically significant difference in the mean infection rates, an

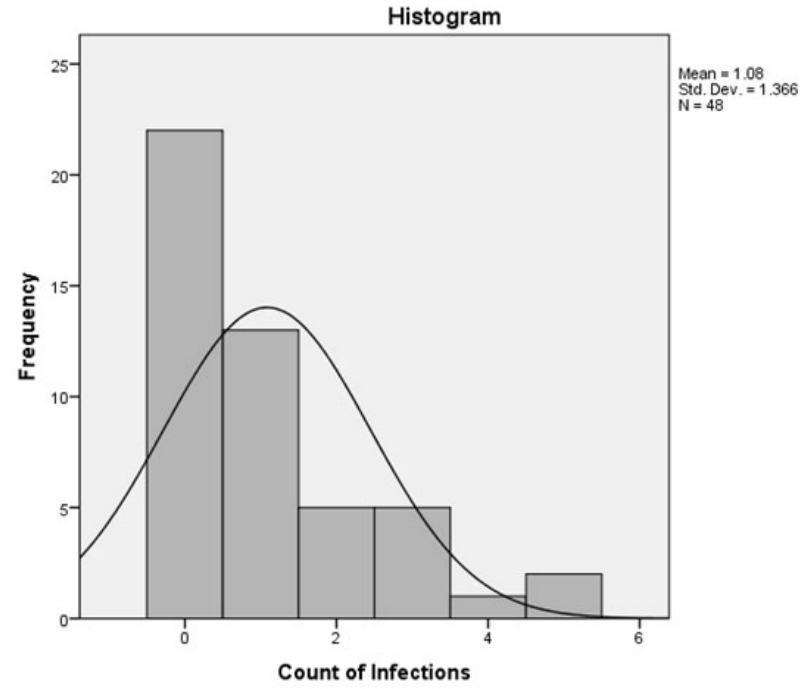

independent sample t-test was performed for the "replacement" and the "non-replacement" units. The distribution of the 48 data points for each group relatively normal, but for both unit types, there was a slight skew to the right (see Figure 8), but the "N" is greater than 30 points for each grouping.

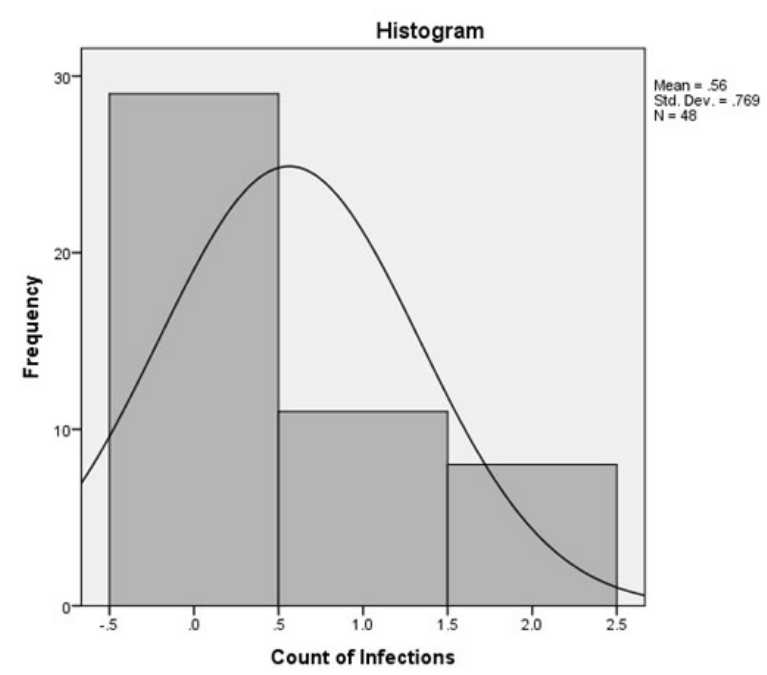

Figure 8. Distribution of central line infection counts in "replacement" versus "non-replacement" units

The mean rate of central line infections for the "replacement" units was 1.08 with a SD of 1.37 , and the mean of central line infections for the "non-replacement" units was 0.56 with a SD of .77. As for the central line days, the homogeneity of variance was significant with a $p=.010$, so that equal variances were not assumed. However, the t-test showed a statistically significant difference in the means of the two groups with the "non-replacement" units having a lower mean number of central venous line infections for the 12 -month period with a $p=.024$. While the $t$-test may be considered less robust with the differences in the variances of the two groups, there is statistical evidence to support that the "non-replacement" units had fewer central line infections in the 12 month period studied, lending credence to the premise that there is limited evidence to support changing out the pressure transducer set-up for fear of increased risk of infection. It should be noted that central venous line infections are impacted by multiple variables. The use of these infection data are not to suggest the non-replacement of the pressure transducer as an infection prevention strategy, but to decrease the fear associated in this organization that there was additional infection risk associated with contamination of the pressure transducers outside the receiving unit.

Table 6. Independent samples T-test "replacement" versus "non-replacement" units for central venous line infections

\begin{tabular}{|c|c|c|c|c|c|c|c|c|c|c|}
\hline & & \multicolumn{2}{|c|}{$\begin{array}{l}\text { Levene's Test for } \\
\text { Equality of Variances }\end{array}$} & \multicolumn{7}{|c|}{$t$-test for Equality of Means } \\
\hline & & \multirow[t]{2}{*}{$\mathbf{F}$} & \multirow[t]{2}{*}{ Sig. } & \multirow[t]{2}{*}{$t$} & \multirow[t]{2}{*}{ df } & \multirow{2}{*}{$\begin{array}{l}\text { Sig } \\
\text { (2-tailed) }\end{array}$} & \multirow{2}{*}{$\begin{array}{l}\text { Mean } \\
\text { Difference }\end{array}$} & \multirow{2}{*}{$\begin{array}{l}\text { Std. Error } \\
\text { Difference }\end{array}$} & \multicolumn{2}{|c|}{$\begin{array}{l}95 \% \text { Confidence Interval } \\
\text { of the Difference }\end{array}$} \\
\hline & & & & & & & & & Lower & Upper \\
\hline \multirow{6}{*}{$\begin{array}{l}\text { Count of } \\
\text { Infections }\end{array}$} & Equal & & & & & & & & & \\
\hline & Variances & 6.976 & .010 & 2.302 & 94 & .024 & .521 & .226 & .072 & .970 \\
\hline & Assumed & & & & & & & & & \\
\hline & Equal & & & & & & & & & \\
\hline & Variances Not & & & 2.302 & 74.095 & .024 & .521 & .226 & .070 & .972 \\
\hline & Assumed & & & & & & & & & \\
\hline
\end{tabular}




\section{Discussion}

The process flow mapping identified several variations in the management of pressure transducers within the organization. For this organization, variation in the process is a gap that should be examined for threats to operational efficiency and cost of care as well as to risk to standards of patient care, which may ultimately impact patient outcomes. An administrative team met to discuss the variations identified, as well as to discuss any improvement interventions that may be implemented. The organization strives to achieve the Institute of Medicine (IOM) quality goals of Safe, Timely, Effective, Efficient, Equitable, Patient-Centered care, ${ }^{[14]}$ and thus the discussion centered on any risk mitigation in the process variation, as well as threats to cost and process efficiency.

The majority of the variation in the process that was identified during the process flow mapping appeared to impact more of the operational efficiency of the organization. In particular, the automatic replacement of the transducer system on four nursing units was determined to be a potential threat to time management and cost efficiency. An example of the time/labor cost could potentially reallocate over $\$ 60,000$ in labor or time-related nursing costs annually in redundancy alone (due to the loss of nursing time on the repetitive task). Standardization of the process, with for example the supplies and equipment, would likely achieve additional direct cost reductions in this process as well. It is estimated the cost of redundant supplies for the replacement process may reach $\$ 162,000.00$ per year.

In addition, through the analysis process, it was determined that supplies and equipment were charged differently to the organization based upon the supply chain representative, and the location of the services. For example, the anesthesia lab was able to procure certain supplies and equipment without additional cost (due to the high volume ordering of other supplies), whereas the nursing units were incurring additional charges. Given these cost efficiency gaps, the leadership team recommended additional analysis of the cost, but recommended a phase two of the project to standardize workflow using PDSA cycle and FMEA process.

The literature has very little information regarding the level or type of provider needed to safely manage the pressure transducer, and no literature to support the education and competency assessments needed to set-up and manage the pressure transducer process. Clearly, an invasive procedure, such as the insertion of a central line should be managed with the highest level of care for safe, quality patient outcomes. However, the level of provider needed to set-up and manage the pressure transducer was a point for discussion. The leadership team, again, believed that this question should be

Published by Sciedu Press answered by the clinical team as a component of creating a standardized workflow. The competency assessment and frequency of the evaluation of this competency would then be developed based upon the provider type and the assessment process for that role.

A related component of the process regarding the type of provider and the workflow redundancy addressed the patterns or outcomes of the process. The initial process mapping identified that the redundancy in the process in the 4 units had been based upon habit. The "why" technique used in event analysis was used to determine the impetus for the replacement process on these 4 units. It was determined that a safety event in the past has resulted in replacement process due to a perceived fear of "unknown" risk of contamination of the placement from another area (like the ED) or another patient care unit. Past experience, however, was not grounded in outcomes or evidence to support the replacement process. Infection data provided by the nursing leadership did not appear to support difference in risk for infection on the units that were not replacing the set-up. In fact, the overall central venous line infection rates were found to be less in those "non-replacement" units when compared to the "replacement units" for the 12 month period of July 2014-June 2015 in the microsystem analysis. However, it is noted, that statistical significance and clinical significance may differ, and the safe, quality care of the patient is ultimately the most important factor.

\section{Conclusion/NeXt STEPS}

Through the microsystem analysis process it was ultimately determined that the answer to the clinical question posed for this improvement project is that the variation in process of pressure transducer set-up and management was impacting the operational efficiency of the organization. Cost variation was found to be attributed to workflow variation, with registered nurse time and potential supply and equipment waste as a direct result of process redundancy. The impact to patient outcomes as determined by risk for central line infections was not determined to be impacted negatively or a factor in increasing line infections for the non-redundant units.

Upon completion of the first phase of this improvement project, the organization used the microsystem analysis data as supporting evidence for a call to decrease variation in the set-up and management of pressure transducers. Process variation of this type over time will impact operational efficiency, but may also impact the standard of patient care and quality patient outcomes. The second phase of this project utilized the small test of change, rapid cycle improvement PDSA process to decrease the variation by establishing a standardized workflow for the set-up and management of pressure trans- 
ducers to mitigate the risk identified through the analysis of this process. The standardization focused on the provider who will be responsible for the set-up and management of the pressure transducer and the required skills and competency assessment, the supplies and equipment used consistently across the organization, and the question of "replacement" versus "non-replacement." The sustainability and efficiency of the revised process flow have not been quantified or studied due to lack of sufficient time post implementation for valid results.
In conclusion, this project highlights the importance of a systematic and robust process for examining clinical workflow within a healthcare organization. Even small variations in processes may result in operational inefficiencies and waste. The use of the three guiding questions of the MFI and the structure of the microsystem analysis provide clarity of goals and quantifiable, actionable data respectively that may be used to impact the IOM aims for quality healthcare.

\section{CONFLiCTS OF INTEREST Disclosure}

The authors declare that there is no conflict of interest.

\section{REFERENCES}

[1] Life in the Fast Lane: Arterial Line. 2015. Available from: http: //lifeinthefastlane.com/ccc/arterial-line/

[2] McGhee B, Bridges E. Monitoring arterial blood pressure: What you may not know. Crit Care Nurse. 2002; 22: 60-79. PMid:11961944

[3] Magee P, Tooley M. The Physics, Clinical Measurement, and Equipment of Anaesthetic practice. Oxford: Oxford Press; 2005.

[4] Miller R, Cohen N, Eriksson L, et al. Miller's Anesthesia 8th Edition. Philadelphia, PA: Elsevier/Saunders. 2015.

[5] Ward M, Langton J. Blood pressure measurement: Continuing education in Anaesthesia. Critical Care and Pain. 2007; 7 (4): 122-126. http://dx.doi.org/10.1093/bjaceaccp/mkm022

[6] Stoker M. Principle of pressure transducers, resonance, damping and frequency response. Anaesthesia and Intensive Care Medicine. 2004; 5(11): 371-375. http://dx.doi.org/10.1383/anes.5.11.371 .53397

[7] Gupta B. Invasive blood pressure monitoring. World Anesthesia Society, Update 23. 2005. Available from: http://worldanaesthesia. org/index.php?option=co m_docman\&task=doc_download\&gid=210\&Itemid $=26$
[8] Anesthesia Tutorial of the Week (ATOW). 2015. Available from: http://www.frca.co.uk/Documents/137\%20Physical $\% 20 \mathrm{pr}$ inciples $\% 20$ of $\% 20$ intra-arterial $\% 20$ blood $\% 20$ pressure $\% 20$ measurement.pdf

[9] Langley G, Moen R, Nolan K, et al. The Improvement Guide: A Practical Approach to Enhancing Organizational Performance (2nd ed.). San Francisco: Jossey-Bass; 2009.

[10] ASQ: American society for quality what is a process flow chart? 2015. Available from: http://asq.org/learn-about-quality /process-analysis-tools/overview/flowchart.html

[11] Nelson E, Batalden P, Godfrey M, et al. Value by Design: Developing Clinical Microsystems to Achieve Organizational Excellence. San Francisco: Jossey-Bass; 2011.

[12] Microsystem Academy: transforming microsystems in healthcare. 2015. Available from: https://clinicalmicrosystem.org/

[13] API: associates in process improvement. 2015. Available from: http://www .apiweb.org/

[14] IOM: crossing the quality chasm: the IOM healthcare quality initiative. 2015. Available from: http://www.iom.edu/Global /NewsAnnouncements/Crossing-the-Quality-Chasm-The -IOM-Health-Care-Quality-Initiative.aspx 